Revta brasil. Bot., São Paulo,V.24, n.4 (suplemento), p.567-576, dez. 2001

\title{
Estudo anatômico foliar do clone híbrido 4430 de Tradescantia: alterações decorrentes da poluição aérea urbana
}

\author{
EDENISE SEGALA ALVES ${ }^{1,3}$, PAULA MATTOS GIUSTI ${ }^{1}$, MARISA DOMINGOS ${ }^{1}$, PAULO H.N. \\ SALDIVA $^{2}$, ELIANE T. GUIMARÃES ${ }^{2}$ e DÉBORA J.A. LOBO ${ }^{2}$
}

(recebido: 4 de setembro de 2000; aceito: 11 de julho de 2001)

\begin{abstract}
Anatomic studies on Tradescantia hibrid clone 4430 leaves: changes caused by urban air pollution). The relationship between the urban air pollution and respiratory diseases of human populations have been confirmed through several epidemiological studies. Continuous monitoring of air pollutant concentrations is perfomed by CETESB (The State Agency of Air Quality Control) in the city of São Paulo. However, biomonitoring programs using plants are other complementary and important ways to measure and prevent the effects of air pollutants on the biological systems and to a certain extent human health. The clone 4430 of Tradescantia has been used in biossays (Trad-MCN, Trad-SH) to monitor the genotoxic potential of several substances. However, the possibility of using the changes in some features of plants from these clones, which are indicators of air pollution effects, has never been explored. Thus, after establishing the structural pattern of these plants, the present study intended to select, among their anatomical characteristics, the most adequate as bioindicators of air quality. Plants of clone 4430 from EMBRAPA-Jaguaríuna (out of the influence of air pollution of São Paulo city - control) were cultivated in parts under standardised conditions and exposed for three months to the environment of three polluted sites of São Paulo: Instituto de Botânica, Cerqueira César and Congonhas. The structural analysis of the leaves revealed the presence of an unstratified epidermis with glandular and non-glandular trichomes in both surfaces, diacytic stomata, mesophyll with only spongy parenchyma, angular collenchyma near to colateral vascular bundles, and water storing cells near the central bundle. No qualitative changes were observed among the leaves from the four studied sites, but significant reductions in the stomata size, metaxylem diameter, and leaf thickness were detected in plants from the polluted sites. The results showed that some structural aspects of the clone 4430 can be used as bioindicators of the effects of the air pollution.
\end{abstract}

RESUMO - (Estudo anatômico foliar do clone híbrido 4430 de Tradescantia: alterações decorrentes da poluição aérea urbana). Estudos epidemiológicos mostram uma relação entre a poluição aérea em centros urbanos e a taxa de doenças respiratórias na sua população. Em São Paulo, a concentração dos principais poluentes aéreos é monitorada pela CETESB porém, tais dados não dão idéia do risco ao qual a população está sujeita; plantas bioindicadoras podem dar idéia deste risco. O clone híbrido 4430 de Tradescantia vem sendo utilizado em bioensaios (Trad-MCN, Trad-SH) que avaliam o efeito genotóxico de várias substâncias. Não há registros das potencialidades de bioindicação relativas à estrutura das folhas do clone. Este estudo objetivou estabelecer o padrão estrutural da folha do clone e verificar se existem características anatômicas afetadas pela poluição, que podem ser utilizadas como bioindicadoras. Para tanto, plantas do clone 4430 procedentes da EMBRAPA-Jaguariúna-SP (fora da influência da poluição da cidade de São Paulo - material controle) foram cultivadas em condições padronizadas e expostas em três pontos distintos da cidade: Instituto de Botânica, Cerqueira César e Congonhas onde permaneceram por três meses. A análise da estrutura da folha mostrou que a mesma apresenta: epiderme uniestratificada com tricomas tectores e glândulares nas duas superfícies, estômatos diacíticos, mesofilo com parênquima lacunoso, frouxamente disposto, colênquima do tipo angular distribuído junto às nervuras, feixes vasculares colaterais e parênquima aquífero na região da nervura central. Qualitativamente não foram observadas variações entre as folhas provenientes dos quatro locais estudados porém, quantitativamente, foram encontradas reduções estatisticamente significativas no tamanho dos estômatos, no diâmetro do metaxilema e na espessura da folha, que podem ser atribuídas ao efeito da poluição. Tais parâmetros anatômicos podem ser utilizados como indicadores do efeito da poluição nessa planta e a mesma pode ser utilizada como bioindicadora do ponto de vista estrutural.

Key words - Urban air pollution, Tradescantia, clone 4430, leaf anatomy, biomonitoring

\section{Introdução}

$\mathrm{O}$ ar das grandes cidades vem apresentando, de forma crescente, substâncias que são inóspitas ou impróprias aos organismos vivos, inclusive aos

1. Instituto de Botânica, Caixa Postal 4005, 01061-970 São Paulo, SP, Brasil.

2. Universidade de São Paulo, Faculdade de Medicina, Av. Dr. Arnaldo 455, 01246-903 São Paulo, SP, Brasil.

3. Autor para correspondência: esegala @ terra.com.br seres humanos, podendo a poluição aérea ser vista também como um caso de saúde pública. Estudos epidemiológicos confirmam essa visão, pois têm mostrado uma relação entre o aumento da poluição aérea em centros urbanos e o aumento de doenças respiratórias na sua população (Henderson et al. 1975, Böhm 1982).

Com mais de 18 milhões de habitantes e uma frota automotiva de cerca de quatro milhões de veículos, que lançam diariamente na atmosfera 
toneladas de poluentes particulados e gasosos (CETESB 1998), São Paulo sofre, como uma grande metrópole, os efeitos da poluição do ar. A situação se agrava no inverno devido às inversões térmicas, que retêm os poluentes nas camadas baixas da atmosfera, provocando episódios agudos de poluição. Estudos realizados na cidade mostraram uma relação entre a poluição atmosférica e a mortalidade infantil (Saldiva et al. 1994) e de idosos (Saldiva et al. 1995), o que demostra a necessidade de se somarem esforços para propor soluções que visem o controle da poluição.

Entre os poluentes gasosos mais freqüentes na atmosfera urbana destacam-se o dióxido de enxofre $\left(\mathrm{SO}_{2}\right)$, os nitratos e óxidos de nitrogênio $\left(\mathrm{NO}_{\mathrm{x}}\right)$, o monóxido de carbono (CO), os fluoretos e os oxidantes fotoquímicos, nome que se dá à mistura de poluentes secundários formados pela reação dos hidrocarbonetos e óxidos de nitrogênio na presença de luz solar, como o ozônio $\left(\mathrm{O}_{3}\right)$ e o peroxiacetil nitratos - PAN $\left(\mathrm{CH}_{3}=\mathrm{OO}_{2} \mathrm{NO}_{2}\right)$. Além dos poluentes gasosos, a atmosfera urbana apresenta grande quantidade de material particulado que corresponde às partículas em suspensão com diâmetro $\leq 50 \mu \mathrm{m}$ (Freedman 1995).

Dados da qualidade do ar, gerados através de medidas físico-químicas dos níveis de poluição, apesar de importantes, não podem ser usados diretamente para prever riscos aos quais a população está sujeita, já que os organismos vivos reagem aos poluentes aéreos e a outros fatores ambientais de maneira integrada. Dessa forma, o biomonitoramento, onde reações da vida são usadas para identificar e/ou caracterizar mudanças antropogeneticamente induzidas na qualidade do ar, é mais eficaz para esse fim (Flores 1987, Arndt \& Schweiger 1991).

De uma maneira geral, as plantas são mais sensíveis à poluição que os animais, incluindo o homem e, portanto, estudos sobre os efeitos dos poluentes na vegetação fornecem subsídios importantes para os programas de controle da poluição do ar.

Várias espécies vegetais têm sido utilizadas como bioindicadoras em programas de biomonitoramento da qualidade do ar. Bennett \& Buchen (1995) afirmam que centenas de espécies já foram testadas incluindo liquens, fungos, briófitas, gimnospermas e angiospermas. As plantas superiores são muito úteis para tal finalidade por serem organismos eucarióticos, com complexidade genética similar à do homem e por serem facilmente cultivadas, mantidas e utilizadas nos estudos, em relação a espécies indicadoras animais. Além disso, muitas plantas possuem ciclos de vida curtos, o que permite uma avaliação dos efeitos causados por perturbações ambientais em curto prazo (Arndt \& Schweiger 1991, Ellenberg 1991).

As respostas das plantas bioindicadoras aos poluentes podem ser observadas tanto em nível macroscópico, através do aparecimento de cloroses, necroses, queda de folhas ou diminuição no seu crescimento, como podem ocorrer em nível genético, estrutural, fisiológico ou bioquímico, não sendo visualmente observadas (Ellenberg 1991). Além dessas respostas, podem ser detectados, também, efeitos clastogênicos da poluição.O clone híbrido 4430 de Tradescantia (T. subcaulis Bush $\mathrm{x} T$. hirsutiflora Bush), por exemplo, tem sido muito utilizado no exterior para avaliar o efeito genotóxico de poluentes, pesticidas e herbicidas (Ma 1983, Rodrigues et al. 1997), através de bioensaios em que se observam mutações em pêlos estaminais (bioensaio Trad-SH) e em células-mãe dos grãos de pólen na fase de tétrades (bioensaio Trad-MCN) (Ma 1981, Rodrigues et al. 1996, 1998). A grande vantagem da utilização de clones de espécies bioindicadoras é a uniformidade genética obtida, que proporciona reduções na variabilidade das respostas e interpretação mais segura dos resultados.

Embora o clone 4430 de Tradescantia seja mundialmente utilizado nos bioensaios Trad-MCN e Trad-SH para avaliar o potencial genotóxico de ambientes alterados, não se tem notícia de que o mesmo tenha sido estudado do ponto de vista estrutural.

Diante disso, este estudo objetivou, inicialmente, estabelecer o padrão estrutural do clone e, em seguida, verificar, através de experimentos de exposição in situ, se existem parâmetros anatômicos da folha que podem ser utilizados como indicadores do efeito da poluição nessa planta, visando sua utilização em programas de biomonitoramento da qualidade do ar. 


\section{Material e métodos}

No estudo foram empregadas plantas de Tradescantia clone 4430, (híbrido de T. subcaulis Bush x T. hirsutiflora Bush - Commelinaceae), produzidas na cidade de Jaguariúna - SP, em casa de vegetação da EMBRAPA, local isento de poluição urbana.

Área de estudo - Foram selecionados três pontos distintos da cidade de São Paulo, a saber: 1. Instituto de Botânica (bairro da Água Funda), em local protegido do tráfego automotivo, portanto submetido a quantidades pouco expressivas de material particulado, $\mathrm{SO}_{2}$ e NO , porém bastante atingido por poluentes foto-oxidantes secundários, como o $\mathrm{O}_{3}$ (Klumpp et al. 1994). 2. Faculdade de Medicina da Universidade de São Paulo (bairro Cerqueira César), ao lado da Estação Cerqueira César da rede telemétrica da CETESB, local de intenso tráfego de veículos e, conseqüentemente, submetido a particulados e gases provenientes da queima de combustíveis. 3. Avenida dos Bandeirantes (bairro Moema), em escola municipal, ao lado da Estação Congonhas da rede telemétrica da CETESB, local também submetido a intenso tráfego automotivo.

Os dados apresentados na tabela 1 indicam as concentrações médias e máximas, para o ano de 1998, dos principais poluentes aéreos, medidos nas estações Cerqueira César e Congonhas.

Folhas das plantas trazidas de Jaguariúna foram fixadas em FAA ${ }^{70}$ (Kraus \& Arduin 1997) e representaram o material controle, que serviu para o estabelecimento do padrão estrutural do clone. Mudas dessas plantas foram produzidas por propagação vegetativa em vasos plásticos (1,5 L de capacidade) com substrato artificial (Plantmax e vermiculita, na proporção 3:1). Após aclimatação em casa de vegetação, cerca de 20 vasos foram distribuídos nos pontos já descritos. As plantas foram expostas a pleno sol por três meses (agosto a outubro/1998) e irrigadas semanalmente com água deionizada até o encharcamento do substrato. Após o período de exposição, foram coletadas folhas de Tradescantia originadas nesse período. Para o estudo foram escolhidas folhas com a mesma largura e aproximadamente o mesmo comprimento que o material controle, que foram fixadas em $\mathrm{FAA}^{70}$.

Amostras foram retiradas da região mediana das folhas provenientes dos três locais de estudo e do local controle e estas foram seccionadas transversalmente à mão-livre. As secções foram clarificadas com hipoclorito de sódio a $20 \%$ e, em seguida, submetidas ao processo de dupla coloração com azul de astra (1\%) e safranina (1\%) aquosos na proporção 9:1 (Johansen 1940), sendo montadas em glicerina a 66\%.

Para a obtenção de material diafanizado das superfícies adaxial e abaxial das folhas, utilizou-se hidróxido de sódio (20\%) e hipoclorito de sódio (20\%). Após clarificação, esse material foi duplamente corado com soluções aquosas de azul de alcião (1\%) e safranina (0,5\%) (Kraus \& Arduin 1997).

Medições e contagens foram realizadas com microscópio dotado de objetiva de tambor e com microscópio de projeção. $\mathrm{O}$ número de estômatos e o número de células epidérmicas foram contados em $1 \mathrm{~mm}^{2}$ na região mediana de três folhas.
Foram avaliados 30 campos de cada uma das superfícies. A partir desses resultados, foi calculado, para cada superfície, o índice estomático através da seguinte expressão: Es. (Es + $E \mathrm{E})^{-1} \cdot 100$, onde Es representa o número de estômatos por unidade de área e Ep o número células epidérmicas da mesma área. Foram quantificados, em mm, o diâmetro dos elementos do metaxilema da nervura central, as dimensões da câmara subestomática (altura/largura), a espessura da lâmina foliar no bordo e na região mediana, a altura das células do mesofilo na região mediana, medida paralelamente à superfície da folha em secção transversal, e o tamanho dos estômatos nas duas superfícies. Estabeleceu-se, também, a freqüência relativa (em porcentagem) do mesofilo da folha em relação à outros tecidos, como a epiderme e feixes vasculares. Para tanto, empregou-se técnica estereológica (Underwood 1970) através da contagem de $\mathrm{Pp}$, que corresponde à fração de ponto por número de pontos teste. Utilizando-se uma grade retangular composta de 25 pontos de cruzamento, contou-se, na seção transversal da folha, quantas vezes células do mesofilo foram interceptadas pelos pontos de cruzamento. $\mathrm{O}$ valor obtido foi dividido pelo número total de pontos (25) e transformado em porcentagem. Para cada local de exposição foram repetidas as contagens em 30 campos diferentes.

Para a determinação das diferenças entre os locais de amostragem, em cada variável quantitativa, aplicou-se análise de variância paramétrica (Teste F) ou não paramétrica (Teste de Kruskal-Wallis), quando não houve distribuição normal e/ ou igualdade de variâncias. Quando o nível de significância $(\mathrm{p}<0,05)$ da análise foi atingido, aplicou-se um teste de comparações múltiplas, paramétrico (Teste $\mathrm{F}$ ) ou não paramétrico (Student-Newman-Keuls), para identificação das diferenças entre os tratamentos $(\mathrm{p}<0,05)$.

\section{Resultados}

A folha de Tradescantia clone 4430 dos espécimes provenientes de Jaguariúna, é simples, séssil, linear, pilosa, com margem ciliada e ápice acuminado; apresenta comprimento médio de $21,5 \mathrm{~cm}$ e largura na região mediana de $0,7 \mathrm{~cm}$, é anfiestomática e seu padrão de nervação é paralelinérvio.

A epiderme das faces adaxial e abaxial é unisseriada; em vista frontal apresenta células alongadas no sentido longitudinal (figuras 1,2). $\mathrm{Na}$ superfície abaxial, a epiderme apresenta maior número de estômatos $\left(29,0 / \mathrm{mm}^{2}\right.$, valores médios para Jaguariúna), enquanto que na adaxial é menor $\left(15,0 / \mathrm{mm}^{2}\right)$ (tabela 2). Os estômatos do tipo diacítico mostram-se, em secção transversal, no mesmo nível ou ligeiramente acima das demais células epidérmicas (figura 3). Na epiderme adaxial registrou-se a presença de células buliformes de 

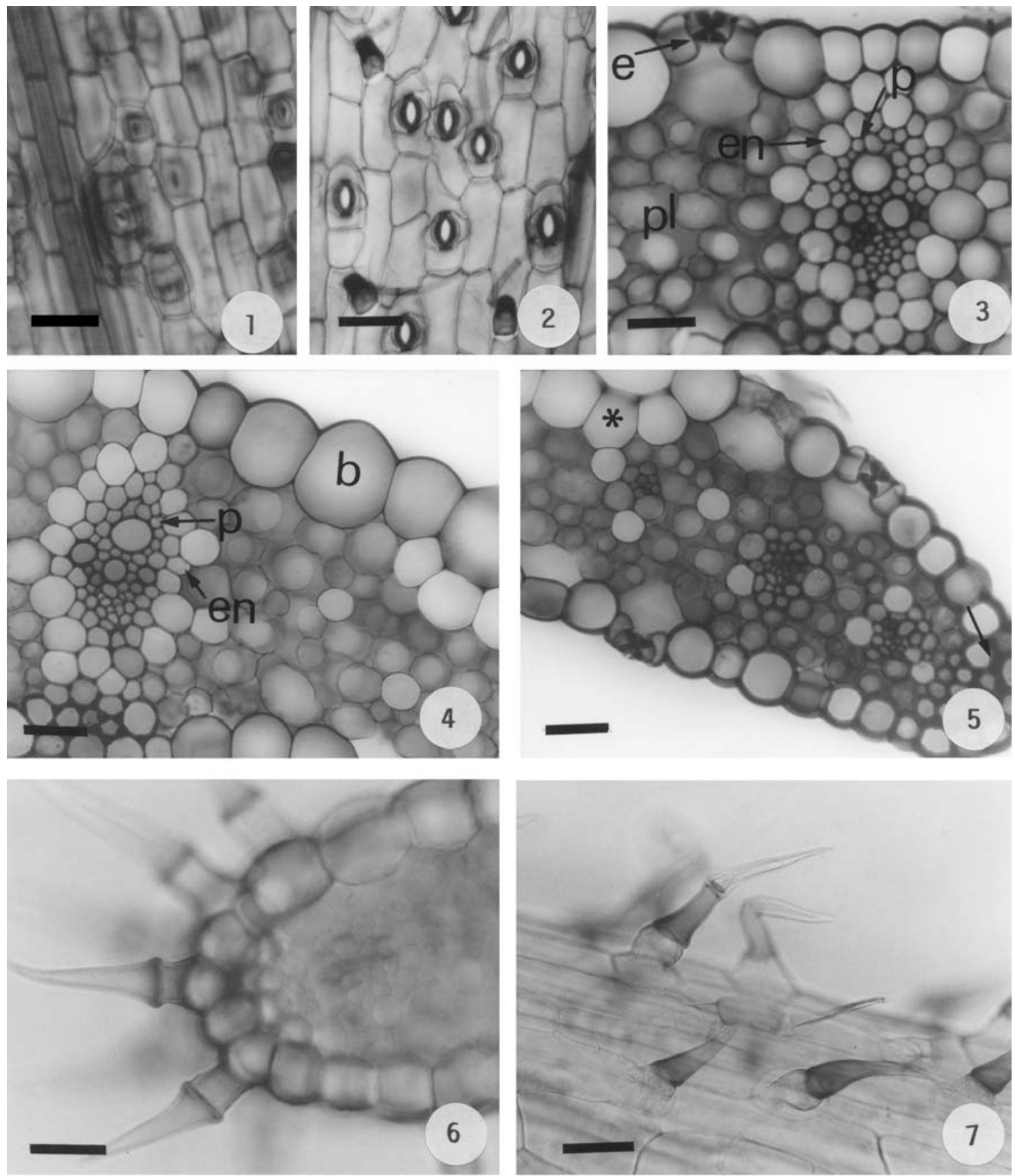

Figuras 1-7. Fotomicrografias da folha de Tradescantia (clone 4430). 1-2. Estômatos em vista frontal (escala = $100 \mu \mathrm{m}) .1$. Superfície adaxial. 2. Superfície abaxial. 3-5. Secções transversais. 3. Estômato (e) ligeiramente acima das demais células epidérmicas, parênquima paliçadico $(\mathrm{pl})$, endoderme $(\mathrm{en})$ e periciclo $(\mathrm{p})($ escala $=50 \mu \mathrm{m})$. 4. Epiderme adaxial com células buliformes (b); feixe vascular, destacando-se endoderme $(\mathrm{en})$ e periciclo $(\mathrm{p})(\mathrm{escala}=50 \mu \mathrm{m})$. 5. Bordo da folha, onde se vê hipoderme aqüífera descontínua $(*)$ e colênquima (seta) $($ escala $=50 \mu \mathrm{m})$. 6. Tricomas tectores no bordo da folha (secção transversal) $($ escala $=30 \mu \mathrm{m})$. 7. Tricomas tectores em vista frontal $($ escala $=50 \mu \mathrm{m})$. 
aspecto globoso característico (figura 4). As células epidérmicas da superfície adaxial apresentam maiores dimensões (figura 5).

Na superfície adaxial, logo abaixo da epiderme, observa-se uma hipoderme aqüífera descontínua (figura 5). No bordo da folha, as células epidérmicas são menores e apresentam cutícula espessada; observa-se nessa região, contígüa à epiderme, a presença de uma ou duas camadas de células com paredes espessadas (colênquima) (figura 5).

Registrou-se a presença de tricomas tectores simples, unisseriados, bicelulares ou tricelulares, com célula basal dilatada e apical afilada (figuras $6,7)$, distribuídos ao longo de toda a superfície da folha, especialmente nos bordos e glândulares simples, unisseriados com até quatro células (figura 8). Ambos os tipos apresentam-se distribuídos nas superfícies adaxial e abaxial, com predominância nesta última.

O mesofilo apresenta parênquima lacunoso, organizado em um número médio de cinco a seis estratos, frouxamente dispostos (figura 9), cujas dimensões celulares encontram-se na tabela 2. Em vista longitudinal, o clorênquima apresenta-se braciforme (figura 10). As folhas apresentam cerca de 14 feixes vasculares colaterais, maiores e menores, que se intercalam e um feixe central bem desenvolvido, proeminente na superfície abaxial (figura 11). Todos os feixes são envolvidos por uma camada de células bem delimitada, a endoderme (figuras 3 e 4). Internamente à ela, observa-se uma camada de células menores que corresponde ao periciclo (figuras 3,4). O feixe central apresenta um córtex no qual se observa a presença de colênquima angular ventralmente e células buliformes dorsalmente (figura 11).

Não foram observadas variações qualitativas na região mediana das folhas dos indivíduos provenientes dos quatro locais de estudo. Características quantitativas como o número de estômatos, o índice estomático e as dimensões das câmaras subestomáticas (altura/largura) (figura 9) não variam significativamente (tabela 2). Variações quantitativas significativas foram encontradas para o tamanho dos estômatos, sendo que aqueles presentes na epiderme abaxial não variaram significativamente entre os locais mais poluídos (Cerqueira César e Congonhas), porém diferiram do controle, sendo menores que os de Jaguariúna (tabela 2).

O diâmetro do metaxilema, medido na nervura principal na região mediana da folha, mostrou-se menor nas plantas expostas aos locais mais poluídos (Cerqueira César e Congonhas) e maior nas plantas provenientes do sítio controle e naquelas expostas no Instituto de Botânica (tabela 2).

A porcentagem de mesofilo em relação aos demais constituintes da folha e a altura das células do parênquima lacunoso não variaram significativamente entre os quatro locais (tabela 2).

A espessura da folha na região do bordo mostrou-se menor nos locais mais poluídos, ao passo que nas folhas expostas no Instituto de Botânica e naquelas procedentes de Jaguariúna não se constatou variação significativa. A espessura da folha na região mediana mostrou-se comparativamente menor apenas nas folhas expostas em Congonhas (tabela 2).

\section{Discussão}

Os poluentes gasosos entram nas folhas principalmente através dos estômatos (Brobov 1955), portanto, suas dimensões e freqüência devem interferir na quantidade absorvida e, conseqüentemente, nos possíveis efeitos que a poluição provoca na planta. Segundo Wellburn (1990), tais efeitos variam também em função de vários fatores como a concentração dos poluentes, o tempo de exposição, a idade da planta, fatores edáficos e intensidade luminosa, causando injúrias

Tabela 1. Concentração média dos principais poluentes do ar de São Paulo no ano de 1998. Fonte: CETESB

\begin{tabular}{lccccc}
\hline Local & $\begin{array}{c}\mathrm{PM}_{10}{ }^{\mathrm{a}} \\
\left(\mu \mathrm{m} \cdot \mathrm{m}^{-3}\right)\end{array}$ & $\begin{array}{c}\mathrm{CO}^{\mathrm{b}} \\
(\mathrm{ppb})\end{array}$ & $\begin{array}{c}\mathrm{SO}_{2}{ }^{\mathrm{a}} \\
\left(\mu \mathrm{g} \cdot \mathrm{m}^{3}\right)\end{array}$ & $\begin{array}{c}\mathrm{O}_{3}{ }^{\mathrm{a}} \\
\left(\mu \mathrm{g} \cdot \mathrm{m}^{3}\right)\end{array}$ & $\begin{array}{c}\mathrm{NO}_{2}{ }^{\mathrm{a}} \\
\left(\mu \mathrm{g} \cdot \mathrm{m}^{3}\right)\end{array}$ \\
\hline Congonhas & 54 & 21 & 18 & 214 & 138 \\
C. César & 40 & 11 & 12 & $\#$ & 109 \\
\hline
\end{tabular}

$\mathrm{PM}^{10}=$ material particulado com até $10 \mu \mathrm{m}$ de diâmetro; (a) valores médios, (b) valores máximos, \# não medido. 

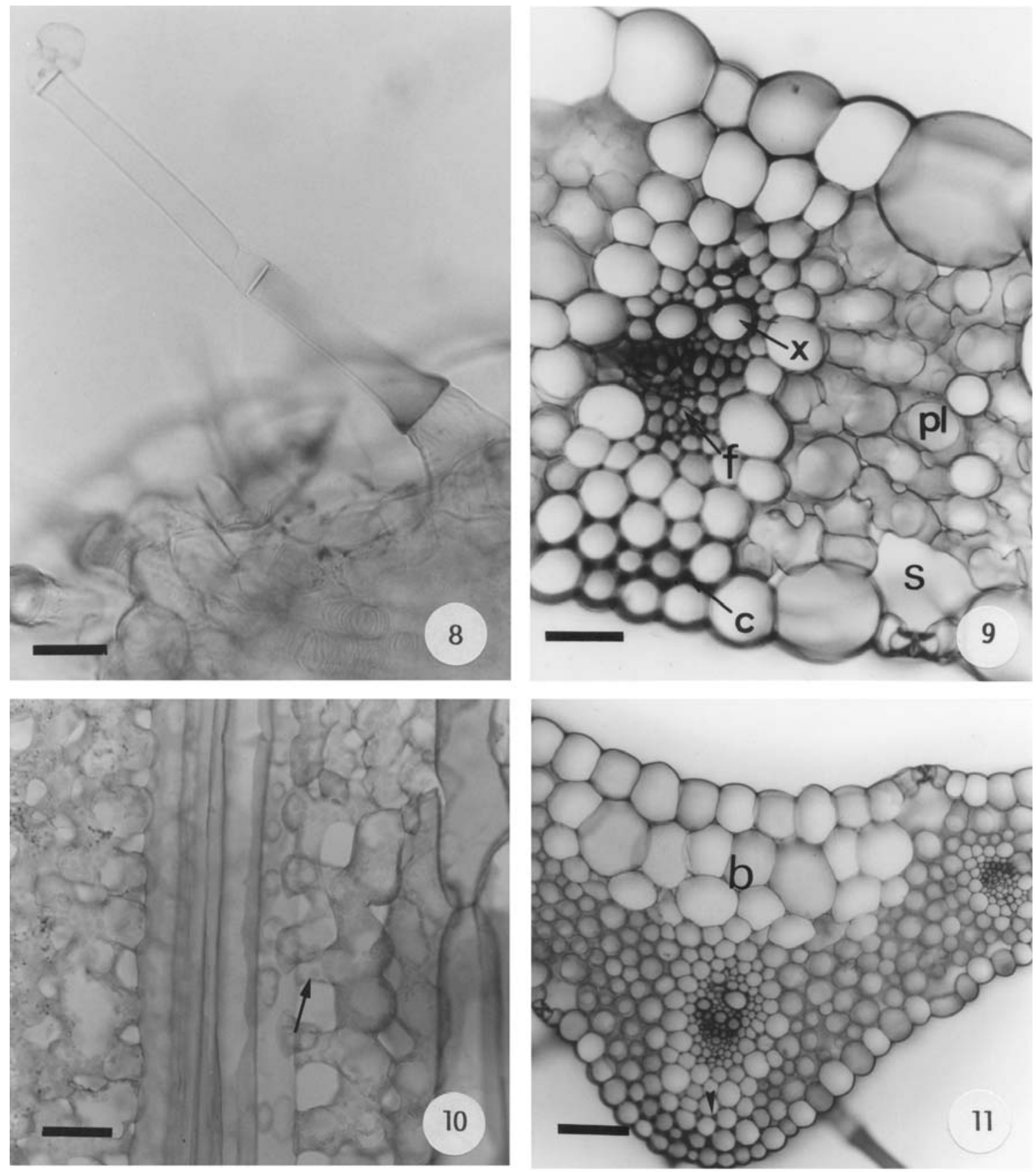

Figuras 8-11. Fotomicrografias da folha de Tradescantia (clone 4430). 8. Tricoma glândular (escala=20 $\mu \mathrm{m}$ ). 9. Secção transversal onde se observam feixe vascular com xilema (x) e floema (f), parênquima lacunoso (pl), colênquima (c) e câmara sub-estomática (s) $($ escala $=40 \mu \mathrm{m})$. 10. Seç̧ão longitudinal com clorênquima braciforme (seta) (escala $=50 \mu \mathrm{m})$. 11. Feixe central no qual se observa a presença de colênquima angular ventralmente (cabeça de seta) e células buliformes dorsalmente (b) (escala $=100 \mu \mathrm{m})$. 
Tabela 2. Quantificação de algumas características anatômicas e morfométricas da folha de Tradescantia clone 4430 expostas nos diferentes locais estudados (quantificações realizadas na região mediana da folha).

\begin{tabular}{|c|c|c|c|c|c|c|c|c|c|c|c|c|}
\hline \multirow{4}{*}{$\begin{array}{l}\text { Característica } \\
\text { Tamanho dos } \\
\text { estômatos }(\mu \mathrm{m})\end{array}$} & \multirow[b]{3}{*}{ Adaxial } & \multicolumn{11}{|c|}{ Locais de exposição } \\
\hline & & \multicolumn{3}{|c|}{ Jaguarúna } & \multicolumn{2}{|c|}{$\begin{array}{l}\text { Instituto de } \\
\text { Botânica }\end{array}$} & \multicolumn{4}{|c|}{$\begin{array}{l}\text { Cerqueira } \\
\text { César }\end{array}$} & \multicolumn{2}{|l|}{ Congonhas } \\
\hline & & 64,0 & $\pm 11,9$ & $a^{*}$ & 72,4 & $\pm 8,0 \mathrm{~b}$ & 66,3 & \pm & 8,1 & $\mathrm{a}$ & $54,2 \pm 4,5$ & $\mathrm{c}$ \\
\hline & Abaxial & 60,5 & $\pm 7,2$ & $\mathrm{a}$ & 50,8 & $\pm 4,0 \mathrm{~b}$ & 56,9 & \pm & 6,0 & $\mathrm{~b}$ & $55,9 \pm 5,7$ & $\mathrm{~b}$ \\
\hline \multirow{2}{*}{$\begin{array}{l}\text { Número de } \\
\text { estômatos }\left(\mathrm{mm}^{2}\right)\end{array}$} & Adaxial & 14,8 & $\pm 3,5$ & $\mathrm{a}$ & 11,3 & $\pm 3,0 \mathrm{a}$ & 13,2 & \pm & 1,7 & $\mathrm{a}$ & $10,3 \pm 2,8$ & $\mathrm{a}$ \\
\hline & Abaxial & 28,6 & $\pm 3,7$ & $\mathrm{~b}$ & 31,4 & $\pm 4,3 \mathrm{~b}$ & 35,7 & \pm & 4,5 & $\mathrm{~b}$ & $36,0 \pm 6,1$ & $\mathrm{~b}$ \\
\hline \multirow{2}{*}{$\begin{array}{l}\text { Número de células } \\
\text { epidérmicas }\left(\mathrm{mm}^{2}\right)\end{array}$} & Adaxial & 35,3 & $\pm 3,8$ & $\mathrm{a}$ & 34,8 & $\pm 2,3 \mathrm{a}$ & 33,5 & \pm & 3,0 & $\mathrm{a}$ & $37,2 \pm 1,8$ & $\mathrm{a}$ \\
\hline & Abaxial & 42,6 & $\pm 9,0$ & $\mathrm{~b}$ & 42,7 & $\pm 3,0 \mathrm{~b}$ & 39,0 & \pm & 2,1 & $\mathrm{~b}$ & $45,7 \pm 3,2$ & $\mathrm{~b}$ \\
\hline \multirow[t]{2}{*}{ Índice estomático } & Adaxial & 15,6 & $\pm 0,4$ & $\mathrm{a}$ & 12,9 & $\pm \quad 0,2 \mathrm{a}$ & 14,2 & \pm & 1,8 & $\mathrm{a}$ & $14,1 \pm 4,1$ & $\mathrm{a}$ \\
\hline & Abaxial & 21,5 & $\pm 3,9$ & $\mathrm{~b}$ & 22,3 & $\pm 1,4 \mathrm{~b}$ & 25,0 & \pm & 0,3 & $\mathrm{~b}$ & $23,1 \pm \quad 0,4$ & $\mathrm{~b}$ \\
\hline \multicolumn{2}{|c|}{$\begin{array}{l}\text { Razão entre altura/largura da câmara } \\
\text { sub- es tomática }\end{array}$} & 0,21 & $\pm 0,06$ & & 0,19 & $\pm 0,5 \mathrm{a}$ & 0,2 & & 0,06 & & $0,2 \pm 0,03$ & \\
\hline \multicolumn{2}{|c|}{ Diâmetro médio do metaxilema $(\mu \mathrm{m})$} & 37,9 & $\pm 4,2$ & a & 41,0 & $\pm 6,2 \mathrm{a}$ & 31,5 & \pm & 4,2 & $\mathrm{~b}$ & $31,2 \pm \quad 6,7$ & $\mathrm{~b}$ \\
\hline \multicolumn{2}{|c|}{$\begin{array}{l}\text { Porcentagem de mesofilo em relação aos } \\
\text { demais tecidos da follha }\end{array}$} & 50,2 & $\pm 6,5$ & $\mathrm{a}$ & 51,6 & $\pm 6,3 \mathrm{a}$ & 56,5 & \pm & 7,6 & $\mathrm{a}$ & $51,9 \pm \quad 5,7$ & $\mathrm{a}$ \\
\hline \multicolumn{2}{|c|}{ Altura das células do meso filo $(\mu \mathrm{m})$} & 32,5 & $\pm 4,3$ & a & 28,7 & $\pm 4,7 \mathrm{a}$ & 31, & \pm & 5,9 & $\mathrm{a}$ & $29,0 \pm \quad 6,0$ & a \\
\hline \multirow{2}{*}{$\begin{array}{l}\text { Espessura da folha } \\
(\mu \mathrm{m})\end{array}$} & Bordo & 292,2 & $\pm 46,8$ & a & 305,1 & $\pm 57,7 \mathrm{a}$ & 262,7 & \pm 1 & 19,2 & $\mathrm{~b}$ & $254,2 \pm 19,2$ & $\mathrm{~b}$ \\
\hline & Região mediana & 740,1 & $\pm 52,2$ & $\mathrm{a}$ & 727,6 & $\pm 41,9 \mathrm{a}$ & 720,3 & \pm 4 & 40,5 & $\mathrm{a}$ & $522,9 \pm 46,2$ & $\mathrm{~b}$ \\
\hline
\end{tabular}

*Letras diferentes, na mesma linha, indicam diferenças significativas $(\mathrm{p}<0,05)$.

visíveis ou invisíveis. As mudanças estruturais observáveis muitas vezes estão ligadas a um decréscimo na taxa de transpiração e na fotossíntese, que pode ser reduzida, entre outros fatores, devido à desagregação das ceras epicuticulares, que chegam a obliterar os estômatos impedindo as trocas gasosas (Viskari et al. 2000). No caso das injúrias invisíveis, embora não se evidencie nenhum sinal óbvio de dano, ocorre redução no crescimento da planta, uma vez que afetando as trocas gasosas, e conseqüentemente a fotossíntese, ocorre um decréscimo no suprimento de carboidratos e de reguladores de crescimento (Kozlowski et al. 1991). No presente estudo procurou-se padronizar a situação de exposição para minimizar o efeito dos fatores externos portanto, a concentração dos poluentes presentes nos diferentes pontos da cidade de São Paulo deve ter sido a responsável pelas variações quantitativas encontradas em alguns dos constituintes da folha do clone 4430 de Tradescantia.
Existem muitos estudos realizados em câmaras de fumigação, que apontam relações entre a sensibilidade de plantas, especialmente em relação ao $\mathrm{O}_{3}$, e tamanho e número de estômatos presentes na folha. Bennett et al. (1992) avaliaram plantas sensíveis e tolerantes ao $\mathrm{O}_{3}$ e verificaram que o número de estômatos por unidade de superfície foi $30 \%$ maior no grupo de plantas sensíveis, quando comparado ao tolerante; os autores atribuíram a sensibilidade à maior penetração de $\mathrm{O}_{3}$, que é facilitada pela maior freqüência de estômatos. Evans \& Miller (1972), ao fumigarem quatro espécies de Pinus com $\mathrm{O}_{3}$, encontraram maior densidade de estômatos nas espécies mais sensíveis. Evans et al. (1996), estudando dicotiledôneas herbáceas, observaram relação positiva entre a sensibilidade da planta ao $\mathrm{O}_{3}$, detectada através de sintomas visíveis na folha, e maior densidade de estômatos. Masuch et al. (1992), investigando acículas de Picea abies, encontraram a mesma relação. 
Existe uma tendência geral para caracteres anatômicos mensuráveis, que relaciona a diminuição no tamanho com o aumento na freqüência do caráter em questão. No presente estudo observou-se que, na superfície abaxial da folha, os estômatos das plantas-controle são maiores que aqueles das plantas expostas aos poluentes aéreos da cidade de São Paulo. $\mathrm{Na}$ epiderme adaxial tal variação não foi constatada. Quando se comparou o número de estômatos com as demais células epidérmicas (índice estomático), não foram encontradas variações significativas. Portanto, nas plantas expostas em São Paulo, houve uma redução no tamanho dos estômatos presentes na superfície abaxial não acompanhada pelo aumento na sua freqüência, o que provoca uma redução na capacidade das trocas gasosas e, conseqüentemente, um menor acesso à entrada de poluentes gasosos. Tal situação pode representar uma adaptação a um ambiente onde a poluição é acentuada, como se observa em Cerqueira César e Congonhas (tabela 1). A redução no tamanho dos estômatos foi constatada apenas na superfície abaxial, uma vez que essa sofre mais intensamente o efeito da poluição aérea. Solberg \& Adams (1956), através de experimentos com fumigação de $\mathrm{HF}$ e $\mathrm{SO}_{2}$ mostraram que na epiderme as células da superfície abaxial são as primeiras a sofrerem danos. Efeitos mais intensos nas células da epiderme abaxial também foram observados por Strehl \& Arndt (1989) em espécies de Tillandsia submetidas à fumigação com esses mesmos gases.

Com relação às câmaras sub-estomáticas, há poucas informações a respeito da relação entre suas dimensões e a maior ou menor suscetibilidade da planta a poluentes gasosos. Brobov et al. (1962) verificaram que câmaras sub-estomáticas grandes e muitos espaços intercelulares podem agravar os danos provocados por poluentes gasosos nas folhas de Nicotiana glutinosa. No presente estudo não foram constatadas alterações nas dimensões das câmaras sub-estomáticas entre o controle e as plantas expostas na cidade de São Paulo. Da mesma forma, Evans \& Miller (1972), utilizando quatro espécies de Pinus fumigadas com $\mathrm{O}_{3}$, não encontraram relação entre a profundidade da câmara e a porcentagem de injúrias presentes nas acículas.

Em folhas de Tradescantia clone 4430 expostas em Cerqueira César e Congonhas constatou-se que, no bordo sua espessura é menor, enquanto na região mediana apenas as plantas expostas em Congonhas apresentaram menor espessura. Bennett et al. (1992) verificaram uma diminuição na espessura da folha de espécies sensíveis, quando comparadas às tolerantes à poluição atmosférica, e atribuíram tal variação à diminuição na espessura do parênquima paliçadico, enquanto que a quantidade de parênquima lacunoso não foi alterada.

O mesofilo da folha de Tradescantia clone 4430 apresenta apenas parênquima lacunoso e tanto a porcentagem relativa desse tecido como a altura das suas células não variaram entre as plantas controle e aquelas expostas em São Paulo (tabela 2). A diminuição na espessura da folha pode ter sido causada por uma diminuição dos espaços intercelulares, o que representaria uma adaptação para dificultar o deslocamento dos poluentes dentro da folha. Eleftheriou (1987) comparando folhas de oliveiras de ambiente rural e urbano, encontrou uma redução de espaços aéreos nas plantas de ambiente urbano e destacou que essa redução pode ser uma estratégia adaptativa ao ambiente submetido à grande quantidade de gases tóxicos.

Variações no tamanho também foram observadas no metaxilema, que se mostrou com menor diâmetro nos locais mais poluídos (Cerqueira César e Congonhas). Redução no diâmetro dos elementos condutores em decorrência do aumento da poluição aérea foi constatada em acículas de Picea abies por Masuch et al. (1992).

Kurczynska et al. (1998), analisando o caule de Picea abies submetida a solo rico e pobre em nitrogênio e fumigada com $\mathrm{O}_{3}$, verificaram que o número de traqueídes formado foi menor em maiores concentrações de $\mathrm{O}_{3}$ e que, nas plantas submetidas a um solo rico em nitrogênio, a espessura da parede das traqueídes do lenho tardio aumentou com a maior concentração desse gás. Ainda com relação ao caule, Alves (1995) comparando espécimes de Cecropia glazioui crescendo em ambientes mais e menos poluídos, na região do complexo industrial de Cubatão em São Paulo, constatou, para as amostras provenientes do local mais poluído, uma diminuição no diâmetro dos vasos e também uma redução no seu comprimento.

Para o xilema secundário do caule, já é consenso que fatores ambientais afetam as dimensões e até o arranjo dos elementos vasculares ( Baas \& Schweingruber 1987, Carlquist 1988, 
Alves \& Angyalossy-Alfonso 2000). Comparativamente, vasos de menor diâmetro e em maior número estão associados a ambientes menos favoráveis (Baas 1982), pois implicam num aumento na segurança no transporte, situação desejável quando a planta está submetida a algum tipo de estresse. Resultados similares foram constatados no presente estudo para o xilema primário da folha, o que indica ser essa uma estratégia que se repete no xilema dos diferentes orgãos.

Os resultados mostraram que Tradescantia clone 4430 exposta em São Paulo sofreu os efeitos da poluição aérea, uma vez que houve uma redução nas dimensões dos estômatos, no metaxilema e na espessura da folha. Tais parâmetros, analisados na região mediana da folha, podem ser usados como bioindicadores do efeito da poluição aérea urbana nessa planta.

Cabe destacar que os resultados aqui obtidos podem ser uma indicação indireta do efeito da poluição no crescimento da planta e reforçam a idéia de que a poluição afeta o balanço hídrico e, conseqüentemente, a taxa de fotossíntese conforme já registrado para outras espécies (Wellburn 1990, Masuch et al. 1992, Viskari et al. 2000).

Agradecimentos - Ao CNPq pela concessão de bolsa de I.C. à P.M. Giusti; ao Dr. Geraldo S. Rodrigues (EMBRAPAJaguariúna) por ter cedido mudas do clone; ao CNPq (proc. 522140/97) e à FAPESP (proc. 1997/6195-3).

\section{Referências bibliográficas}

ALVES, E.S. 1995. The effects of the pollution on wood of Cecropia glazioui (Cecropiaceae). IAWA Journal 16:69-80.

ALVES, E.S. \& ANGYALOSSY-ALFONSO, V. 2000. Ecological trends in the wood of some Brazilian species 1: growth rings and vessels. IAWA Journal 21:3-30.

ARNDT, U. \& SCHWEIGER, B. 1991. The use of bioindicators for environmental monitoring in tropical and subtropical countries. In Biological monitoring signals from the environment (H. Ellenberg,ed.). Vieweg, Braunschweig, p.199-298.

BAAS, P. 1982. Systematic, phylogenetic and ecological wood anatomy - History and perspectives. In New perspectives in wood anatomy. (P. Baas, ed.). The Hangue Martinus Nijhoff Publishers, Leiden, p.23-58.

BAAS, P. \& SCHWEINGRUBER, F.H. 1987. Ecological trends in the wood anatomy of trees, shrubs and climbers from Europe. IAWA Bulletin n.s. 8:245-274.

BENNET, J.P. \& BUCHEN, M.J. 1995. Bioleff: three databases on air pollution effects on vegetation. Environmental Pollution 88:262-265.
BENNET, J.P., RASSAT, P., BERRANG, P. \& KARNOSKY, D.F. 1992. Relationships between leaf anatomy and ozone sensitivity of Fraxinus pennsylvanica Marsh. and Prunus serotina Ehrh. Environmental and Experimental Botany 32:33-41.

BÖHM, G.M. 1982. Air pollution and lung cancer. Cancer Detection and Prevention 5:371-374.

BROBOV, R.A. 1955. The leaf structure of Poa annua with observations on its smog sensitivity in Los Angeles county. American Journal of Botany 42:467-474.

BROBOV, R., GLATER, R.A., SOLBERG, A. \& SCOTT, F.M. 1962. A developmental study of the leaves of Nicotiana glutinosa as related to their smog-sensitivity. American Journal of Botany 49:954-970.

CARLQUIST, S. 1988. Comparative wood anatomy: systematic, ecological and evolutionary aspects of dicotyledons wood. Springer Verlag, Berlin.

CETESB. 1998. Relatório da qualidade do ar no Estado de São Paulo. 1997. Série Relatórios, São Paulo.

ELEFTHERIOU, E.P. 1987. A comparative study of the leaf anatomy of olive trees growing in the city and the country. Environmental and Experimental Botany 27:105-117.

ELLENBERG, H. 1991. Bioindicators and biological monitoring. In Biological monitoring. signals from the environment (H. Ellenberg, ed.). Vieweg, Braunschweig, p.13-127.

EVANS, L.S. \& MILLER, P.R. 1972. Comparative needle anatomy and relative ozone sensitivity of four pine species. Canadian Journal of Botany 50:1067-1071.

EVANS, L.S., ALBURY, K. \& JENNINGS, N. 1996. Relationships between anatomical characteristics and ozone sensitivity of leaves of several herbaceous dicotyledonous plant species at Great Smoky Mountains National Park. Environmental and Experimental Botany 36:413-420.

FLORES, F.E.V. 1987. O uso de plantas como bioindicadores de poluição no ambiente urbano-industrial: experiências em Porto Alegre, RS, Brasil. Tübinger Geographische Studien 96:79-86.

FREEDMAN, B. 1995. Environmental ecology. Academic Press Inc. $2^{\mathrm{a}}$ ed. San Diego.

HENDERSON, B.E., GORDON, R.J., MENCK, H., SOOHOO, J., MARTIN, S.P. \& PIKE, M.C. 1975. Lung cancer and air pollution in Southcentral Los Angel country. American Journal of Epidemiology 101:477-488.

JOHANSEN, D.A. 1940. Plant microtechnique. MacGrawHill Book Company, New York.

KLUMPP, A. KLUMPP, G. \& DOMINGOS, M. 1994. Plants bioindicators of air pollution at the Serra do Mar near the industrial complex of Cubatão, Brazil. Environmental Pollution 85:109-116.

KOZLOWSKI, T.T., KRAMER, P.J. \& PALLARDY, S.G. 1991. The physiological ecology of woody plants. Academic Press, San Diego.

KRAUS, J.E. \& ARDUIN, M. 1997. Manual básico de métodos em morfologia vegetal. Editora Universidade Rural, Rio de Janeiro. 
KURCZYNSKA, E.U., BASTRUP-BIRK, A. \& MORTENSEN, L. 1998. Influence of ozone and soil nitrogen content on the stem anatomy os Norway spruce saplings grown in open-top chambers. Environmental and Experimental Botany 49:113-121.

MA, T.S. 1981. Tradescantia micronucleus biossay and pollen tube chromatid aberration test for in situ monitoring and mutagen screening. Environmental Health Perspectives 37:85-90.

MA, T.H. 1983. Tradescantia micronuclei (Trad-MCN) test for environmental clastogens. In In vitro toxicity testing of environmental agents. (Kolber, Wong, Grant, DeWoskin, Hughes, eds.). Plenum Publishing Corporation, New York, p.1191-214.

MASUCH, G., FRANZ, J.T., KICINSKI, H.G. \& KETTRUP, A. 1992. Histological and biochemical differences of slightly and severely injured spruce needles of two stands in Northrhine Westphalia. Environmental and Experimental Botany 32:163-182.

RODRIGUES, G.S., MA, T.H., PIMENTEL, D. \& WEINSTEIN, L.H. 1997. Tradescantia biossays as monitoring systems for environmental mutagenesis - a review. Critical Reviews in Plant Sciences 16:325-359.

RODRIGUES, G.S., MA, T.H., PIMENTEL, D. \& WEINSTEIN, L.H. 1998. In situ assessment of pesticide genotoxity in an integrated pest management program I - Tradescantia micronucleus assay. Mutation Reserch 412:235-244.

RODRIGUES, G.S. MADKOUR, S.A. \& WEINSTEIN, L.H. 1996. Genotoxic activity of ozone in Tradescantia. Environmental and Experimental Botany 36:45-50.
SALDIVA, P.H.N., LICHTENFELS, A.J.F.C., PAIVA, P.S.O, BARONE, I.A, MARTINS, M.A, MASSAD, E., PEREIRA, J.C.R., XAVIER, V.P., SINGER, J.M. \& BÖHN, G.M. 1994. Association between air pollution and mortality due to respiratory diseases in children in São Paulo: a preliminary report. Environmental Research 65:218-225.

SALDIVA, P.H.N., POPE, C.A. III, SCHWARTZ, J., DOCKERY, D., LICHTENFELS, A.J.F.C., SALGE, J.M., BARONE, I.A. \& BÖHN, G.M. 1995. Air pollution and mortality in elderly people: a timesseries in São Paulo. Archives of Environmental Health 50:159-163.

SOLBERG, R.A. \& ADAMS, D.F. 1956. Histological response of some plants leaves to hydrogen fluoride and sulfur dioxide. America Journal of Botany 43:755-760.

STREHL, T. \& ARNDT, U. 1989. Alterações apresentadas por Tillandsia aeranthos e T. recurvata (Bromeliaceae) expostas ao $\mathrm{HF}$ e $\mathrm{SO}_{2}$. Iheringia, série botânica 39:3-17.

UNDERWOOD, E.E. 1970. Quantitative stereology. AddisonWesley Publishing Company Reading, Massachusetts.

VISKARI, E.L., HOLOPAINEN, T. \& KÄRENLAMPI, L. 2000. Responses of spuce seedlings (Picea abies) to exhaust gas under laboratory conditions-II ultrastructural changes and stomatal behaviour. Environmental Pollution 107:99-107.

WELLBURN, A.R. 1990. Tansley Review No 24. Why are atmospheric oxides of nitrogen usually phytotoxic and not alternative fertilizers? New Phytology 115:395-429. 